\title{
Simulation of remote sensing satellite motion base on two line element sets for search and rescue at sea.
}

\author{
Thanh Sach Nguyen ${ }^{1,}{ }^{*}$, Hai Hong Vu Le ${ }^{1}$, Chinh Van Doan ${ }^{1}$, Thai Huy Le ${ }^{2}$ \\ ${ }^{1}$ Military Technical Academy, Hanoi, Vietnam \\ 2108 Military Central Hospital, Hanoi, Vietnam
}

ARTICLE INFO ABSTRACT

Article history:

Received 23rd Aug. 2021

Revised $27^{\text {th }}$ Dec. 2021

Accepted 02 ${ }^{\text {nd }}$ Feb. 2022

Keywords:

Remote sensing satellite,

Satellite orbit,

Search and rescue,

Two - line element.
Nowadays, satellite remote sensing technology has been applied in many fields of socio-economic development, including search and rescue at sea. Systems with the integration of remote sensing satellite technology have made the search and rescue operations faster, more accurate and more efficient. With the search and rescue systems at sea, remote sensing satellite motion simulation is an important task. This helps the authorities to identify and select the appropriate remote sensing satellite image data source to assist in processing and zoning search and rescue at sea. However, in Vietnam, it is difficult to determine the satellite image data source for the search and rescue situations. Therefore, the research team built a remote sensing satellite motion simulation program based on two-line element data. This is the data source that has been used in astronomy research. This program will simulate satellite orbits in real time and at any time. The accuracy evaluation result of satellite orbit simulation have been compared with online remote sensing satellite tracking systems in the world. The research result show that the satellite orbit simulation has ensured accuracy.

Copyright (C) 2022 Hanoi University of Mining and Geology. All rights reserved.

${ }^{*}$ Corresponding author

E - mail: thanhns.geo@lqdtu.edu.vn

DOI: 10.46326/JMES.2022.63 (1).05 


\title{
Tạp chí Khoa học Kỹ thuật Mỏ - Địa chất
}

Trang điện tử: http://tapchi.humg.edu.vn

\section{Mô phỏng sự chuyển động vệ tinh viễn thám dựa trên dữ liệu phần tử hai dòng hỗ trợ tìm kiếm cứu nạn trên biển}

\author{
Nguyễn Sách Thành ${ }^{1,}{ }^{*}$, Lê Vũ Hồng Hải ${ }^{1}$, Đoàn Văn Chinh ${ }^{1}$, Lê Huy Thái ${ }^{2}$ \\ ${ }^{1}$ Học viện Kỹ thuật Quân sự, Hà Nội, Việt Nam \\ 2 Bệnh viện Trung ương Quân đội 108, Hà Nội, Việt Nam
}

\begin{abstract}
THÔNG TIN BÀI BÁO
TÓM TẮT

\section{Quá trình:}

Nhận bài 23/8/2021

Sửa xong $27 / 12 / 2021$

Chấp nhận đăng 02/02/2022

\section{Tù̀ khóa:}

Phần tử hai dòng,

Quỹ đạo vệ tinh,

Tìm kiếm cứu nạn,

Vệ tinh viễn thám.

Ngày nay, công nghê vệ tinh viễn thám đã được úng dưng trong nhiều lĩnh vực phát triên kinh tế xẫ hội, trong đó có lĩnh vực tìm kiếm cúu nạn trên biển. Các hệ thống có sự tích hợp công nghê vệ tinh viễn thám đã giúp các hoạt động tìm kiếm cúu nạn nhanh chóng, chính xác và hiệu quả hơn. Với các hệ thống tìm kiếm cứu nạn trên biển, việc mô phỏng chuyển động vệ tinh viễn thám là một nhiệm vu quan trọng. Điều này giúp các cơ quan chức năng có thể xác định và lựa chon nguồn dư liệu ảnh vê tinh viễn thám phù hợ, nhằm hỗ trơ quá trình xử lý, khoanh vùng tìm kiếm cứu nạn trên biển. Tuy nhiên, ở Viềt Nam việc xác định nguồn dư liệu ảnh vệ tinh cho các tình huống tìm kiếm cúu nạn còn gặp khó khăn. Bỏi vậy, nhóm nghiên cúu đã xây dựng chưong trình mô phỏng chuyển động vệ tinh viễn thám dựa trên dữ liẹu phần tử hai dòng. Đây là nguồn dũ liệu đẫ được sử dụng trong nghiên cúu thiên văn học. Chương trình này sẽ mô phỏng các quỹ đạo vệ tinh trong thời gian thực và ở thời điểm bất kỳ. Kết quả đánh giá độ chính xác của việc mô phỏng quỹ đạo vệ tinh đã được so sánh với các hệ thống trực tuyến theo dõi vệ tinh viển thám trên thế giới. Kết quả nghiên cứu cho thấy việc mô phỏng quỹ đạo vệ tinh đã đảm bảo độ chính xác.
\end{abstract}

(C) 2022 Trường Đại học Mỏ - Địa chất. Tất cả các quyền được bảo đảm.

\section{Mở đầu}

Sự chuyển động của vệ tinh có thể được dự đoán, mô phỏng lại dựa trên dữ liệu tập phần tử hai dòng (Two Line Element - TLE). Đây là định dạng dữ liệu mã hóa danh sách các phần tử quỹ đạo của vật thể quay quanh Trái đất tại một thời điểm nhất định. Hiện nay, có nhiều công trình khoa học đã

\section{${ }^{*}$ Tác giả liên hệ}

E- mail: thanhns.geo@lqdtu.edu.vn

DOI: 10.46326/JMES.2022.63(1).05 ứng dụng dữ liệu TLE trong nghiên cứu sự chuyển động của các vật thể xung quanh trái đất. David và Paul (2012) đã thực hiện nghiên cứu tổng hợp về ứng dụng, thực hành dữ liệu phần tử hai dòng trong thiên văn học. Aleksander và nnk. (2016) đã trình bày phương pháp phân tích TLE nhằm nâng cao khả năng dự đoán sự va vào nhau của các đối tượng hay các sự kiện không gian bên ngoài trái đất. Szabo và nnk. (2019) đã sử dụng MATLAB Live Editor để tính toán quỹ đạo vệ tinh nhỏ dựa trên dữ liệu TLE. Ngoài ra còn kể đến các nghiên cứu khác như Tom và nnk. (2007); Tim và nnk. (2008); Shkelzen và nnk. (2010). 
Trong tìm kiếm cứu nạn, chương trình mô phỏng sự chuyển động vệ tinh viễn thám có vai trò quan trọng trong việc xác định, cung cấp hình ảnh thời gian thực. Đây là phân hệ không thể thiếu trong các hệ thống thông tin tích hợp tìm kiếm cứu nạn. Từ năm 1985, các quốc gia như Canada, Pháp, Nga và Mỹ đã phối hợp, thành lập hệ thống vệ tinh Cospas - Sarsat nhằm thu nhận các thông tin báo động cấp cứu và thông tin vị trí tai nạn trên khắp thế giới, phục vụ đắc lực cho công tác tìm kiếm cứu nạn. Hệ thống Cospas - Sarsat sử dụng vệ tinh quỹ đạo cực tầm thấp kết hợp với vệ tinh quỹ đạo địa tĩnh mang lại độ tin cậy, tăng cường khả năng hỗ trợ tối đa của hệ thống trong công tác tìm kiếm cứu nạn (Jesse, 2013; Shkelzen và nnk., 2010). Hình 1 là mô hình tổng quan của hệ thống Cospas - Sarsat. Chang và nnk. (2002) đã nghiên cứu và xây dựng các quỹ đạo vệ tinh viễn thám cận trái đất bằng cách sử dụng dữ liệu TLE và GPS do Bộ Chỉ huy Phòng không Bắc Mỹ (NORAD) cung cấp. Stefan và nnk. (2007) đã trình bày việc xây dựng nhanh bản đồ hỗ trợ quản lý thảm họa và khủng hoảng dựa trên dữ liệu vệ tinh đa nguồn được thu nhận từ hệ thống giám sát các vệ tinh quan sát trái đất của trung tâm thông tin xử lý khủng hoảng của Đức, nhằm hỗ trợ cho các nhiệm vụ xử lý các tình huống thiên tai lớn, các hoạt động cứu trợ nhân đạo quốc tế như sóng thần ở Ấn Độ dương, lập bản đồ cháy rừng cho Bồ Đào Nha, đánh giá động đất ở Pakistan,... Francesco và nnk. (2015) đã thực hiện dự án nghiên cứu nhằm đánh giá tính khả thi của một hệ thống để theo dõi các luồng nhập cư ở Nam Địa Trung Hải bằng cách dựa vào dữ liệu ảnh vệ tinh viễn thám miễn phí và thương mại thời gian thực. Nguồn dữ liệu này được xác định dựa trên các quỹ đạo của vệ tinh viễn thám.

Ở Việt Nam, các nghiên cứu liên quan tới sự chuyển động của vệ tinh viễn thám chưa nhiều. Bùi và nnk. (2018) đã thực hiện nghiên cứu, đánh giá khả năng phối hợp chụp ảnh của các hệ thống vệ tinh nhỏ dựa trên dữ liệu TLE, thử nghiệm với vệ tinh VNREDSat - 1 và BKA. Mục đích của nghiên cứu là làm giảm thời gian chụp lặp lại và tăng diện tích phủ trùm trong theo dõi, giám sát các đối tượng trên bề mặt trái đất, đặc biệt là các thảm họa tự nhiên hay nhân tạo.

Hiện nay, Biển Đông là một trong những tuyến đường hàng hải quan trọng nhất thế giới. Đây cũng là khu vực có lượng tàu cá hoạt động đông đảo. Vì vậy, việc nâng cao chất lượng, hiệu quả công tác tìm kiếm cứu hộ cứu nạn có ý nghĩa hết sức quan trọng. Thời gian gần đây, trên vùng

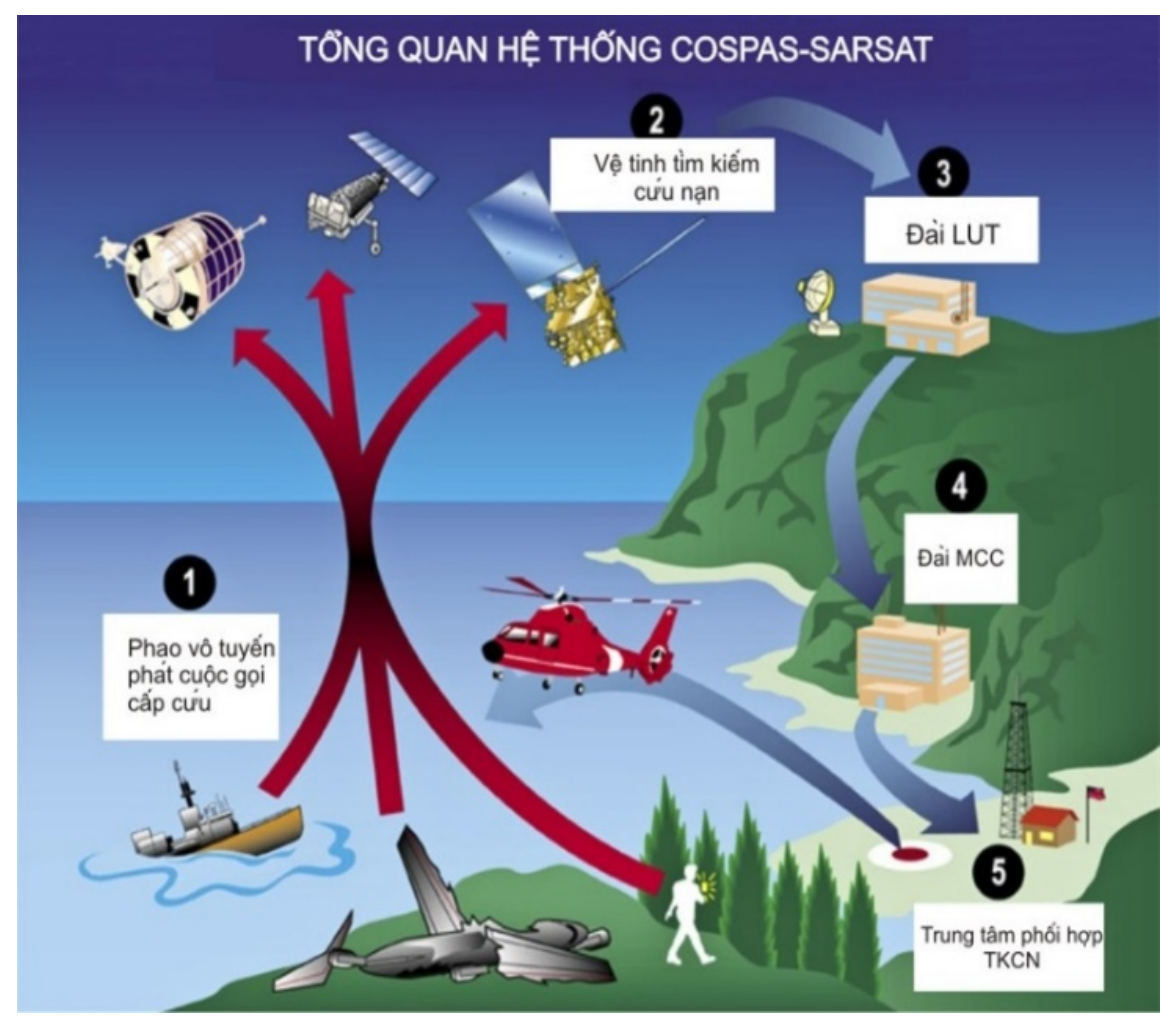

Hình 1. Tổng quan hệ thống COSPAS-SARSAT. 
Biển Đông số vụ tai nạn, sự cố trên biển gia tăng do thiên tai, các hoạt động hàng hải, khai thác hải sản, dầu khí, du lịch, quốc phòng - an ninh,... Ngô (2019) đã báo cáo trong hội nghị công tác tìm kiếm cứu nạn trên biển, trong 8 tháng đầu năm 2019, toàn quốc xảy ra 514 vụ với 2742 người, 317 phương tiện gặp nạn, làm chết 57 người, mất tích 101 người, bị thương 141 người và chìm 132 phương tiện. Công tác tìm kiếm cứu nạn đã cứu được 431 vụ/với 2584 người, 1472 phương tiện. Bởi vậy, hiệu quả của công tác tìm kiếm cứu nạn trên biển có ý nghĩa rất quan trọng, giúp đảm bảo an toàn con người, tài sản và an ninh quốc gia trên biển. Việc ứng dụng khoa học kỹ thuật, đặc biệt là công nghệ vệ tinh viễn thám có ý nghĩa quan trọng do công tác tìm kiếm cứu nạn hiện nay ở các cơ quan chính phủ còn gặp nhiều khó khăn. Việc nghiên cứu, mô phỏng sự chuyển động của vệ tinh viễn thám là quan trọng; điều này sẽ xác định nguồn dữ liệu hợp lý, nhằm giám sát, đánh giá, tìm cứu cứu nạn,...

\section{Dữ liệu và phương pháp nghiên cứu}

\subsection{Tập phần tử hai dòng}

Tập phần tử hai dòng (TLE) bao gồm các phần tử mã ASCII hai dòng với 69 cột, có thể được sử dụng cùng với mô hình quỹ đạo SGP4/SDP4 của NORAD nhằm xác định vị trí và vận tốc của vệ tinh (David và Paul, 2012). Bảng 1 thể hiện thông tin của các trường dữ liệu TLE của trạm vũ trụ quốc tế. Trong tập phần tử hai dòng, các ký tự hợp lệ bao gồm các số $0 \div 9$, các chữ cái viết hoa $A \div Z$, dấu chấm, dấu cách và các dấu cộng và trù̀ (Lihua và nnk., 2016). Hình 2 là dữ liệu TLE đối với trạm vũ trụ quốc tế.

Bảng 1. Thông tin các trường dũ liệu TLE của trạm vũ trụ quốc tế.

\begin{tabular}{|c|c|c|c|}
\hline \multicolumn{4}{|c|}{ Dòng tiêu đề } \\
\hline Trường & Cột & Nội dung & Vídụ \\
\hline 1 & $01 \div 24$ & Tên vệ tinh & ISS (ZARYA) \\
\hline \multicolumn{4}{|c|}{ Dòng thứ nhất } \\
\hline 1 & $01 \div 01$ & Số dòng & 1 \\
\hline 2 & $03 \div 07$ & Số hiệu vệ tinh & 25544 \\
\hline 3 & $08 \div 08$ & Sự phân loại (U=Chưa được phân loại, C=đã phân loại, S=bảo mật) & $\mathrm{U}$ \\
\hline 4 & $10 \div 11$ & Mã định danh quốc tế (2 số cuối của năm phóng vệ tinh) & 98 \\
\hline 5 & $12 \div 14$ & Mã định danh quốc tế (số phóng vệ tính của năm) & 067 \\
\hline 6 & $15 \div 17$ & Mã định danh quốc tế (số hiệu phóng của vệ tinh) & $\mathrm{A}$ \\
\hline 7 & $19 \div 20$ & Thời điểm tham chiếu tập hợp tham số quỹ đạo (Epoch) (2 số cuối của năm) & 98 \\
\hline 8 & $21 \div 32$ & Epoch (ngày trong năm và phần phân số là thời gian trong ngày & 264.51782528 \\
\hline 9 & $34 \div 43$ & Đạo hàm cấp 1 của chuyển động trung bình & -00002182 \\
\hline 10 & $45-52$ & Đạo hàm cấp 2 của chuyển động trung bình & $00000-0$ \\
\hline 11 & $54 \div 61$ & Thuật ngũ̃ BSTAR drag & $-11606-4$ \\
\hline 12 & $63 \div 63$ & Kiểu Ephemeris (sử dụng nội bộ - luôn bằng 0 với dư liệu TLE được phân phối & 0 \\
\hline 13 & $65 \div 68$ & Số tập hợp phần tử & 292 \\
\hline 14 & $69 \div 69$ & Mã kiểm tra dữ liệu (phép dư cho 10) & 7 \\
\hline \multicolumn{4}{|c|}{ Dòng thứ hai } \\
\hline 1 & $01 \div 01$ & Số dòng & 2 \\
\hline 2 & $03 \div 07$ & Số hiệu vệ tinh & 25544 \\
\hline 3 & $09 \div 16$ & Độ nghiêng & 51.6416 \\
\hline 4 & $18 \div 25$ & Xích kinh độ & 247.4627 \\
\hline 5 & $27 \div 33$ & Độ lệch tâm & 0006703 \\
\hline 6 & $35 \div 42$ & Tham số của Perigee & 130.5360 \\
\hline 7 & $44 \div 51$ & Dị thường trung bình & 325.0288 \\
\hline 8 & $53 \div 63$ & Chuyển động trung bình (số vòng quay mỗi ngày) & 15.72125391 \\
\hline 9 & $64 \div 68$ & Số vòng quay tại thời điểm epoch & 56353 \\
\hline 10 & $69 \div 69$ & Mã kiểm tra dữ liệu (phép dư cho 10) & 7 \\
\hline
\end{tabular}


ISS (ZARYA)

125544 U 98067A 88264.51782528 $-.00002182 \quad 80000-\theta \quad-11606-4 \quad 0 \quad 2927$

$\begin{array}{llllllll}2 & 25544 & 51.6416 & 247.4627 & 0006703 & 130.5360 & 325.0288 & 15.72125391563537\end{array}$

Hình 2. Dũ liệu TLE đối với trạm vũ trụ quốc tế.

\subsection{Phương pháp nghiên cúru}

Phương pháp nghiên cứu được thực hiện dựa trên nghiên cứu lý thuyết các định luật Kepler về chuyển động thiên thể và các mô hình nhiễu loạn rút gọn (Simplified perturbations models - SGP) kết hợp với nghiên cứu ứng dụng các nền tảng hỗ trợ xử lý thiên văn và hệ thông tin địa lý. Nhà thiên văn học người Đức Johannes Kepler (1571 - 1630) phát hiện ra rằng các hành tinh chuyển động theo quỹ đạo elip hơn là quỹ đạo tròn và các yếu tố ảnh hưởng tới quỹ đạo bao gồm: độ nghiêng quỹ đạo, xích kinh độ, chuyển động trung bình, độ lệch tâm, dị thường trung bình (Flemming, 2001). Theo Định luật Kepler, chuyển động trung bình của vệ tinh được tính theo công thức (Flemming, 2001):

$$
v^{2}=\frac{G M}{r}
$$

Trong đó: v - vận tốc của vệ tinh (m/s), G hằng số hấp dẫn $G=6.67408 \times$ $10^{-11} \mathrm{Nm}^{2} \mathrm{~kg}^{-2}$; $\mathrm{M}$ - khối lượng của trái đất $M=$ $5.98 \times 10^{24} \mathrm{~kg} ; \mathrm{r}$ - khoảng cách từ tâm trái đất tới vệ tinh (m).

Chu kỳ là khoảng thời gian của quỹ đạo vệ tinh xung quanh trái đất được cung cấp bởi công thức:

$$
T=2 \pi \sqrt{\frac{r^{3}}{G M}}
$$

Độ lệch tâm được tính theo công thức:

$$
e=\sqrt{1-\frac{b^{2}}{a^{2}}}
$$

b - bán trục nhỏ, a - bán trục lớn. Dị thường trung bình được tính theo công thức:

$$
M=\frac{2 \pi(t-t 0)}{T}
$$

Dị thường lệch tâm được tính theo công thức:

$$
E=M+e \times \sin (E)
$$

Dữ liệu TLE được xây dựng dựa trên mô hình nhiễu loạn rút gọn nhằm xác định trạng thái tại thời điểm cần quan tâm. Mô hình nhiễu loạn rút gọn là một bộ gồm năm mô hình toán học (SGP, SGP4, SDP4, SGP8 và SDP8) được sử dụng để tính toán vectơ trạng thái quỹ đạo của vệ tinh và mảnh vỡ không gian so với hệ tọa độ quán tính hướng tâm trái đất. Tập hợp các mô hình này thường được gọi chung là SGP4. Các mô hình này sẽ dự đoán ảnh hưởng của các yếu tố nhiễu loạn do hình dạng, lực cản, bức xạ và lực hấp dẫn của Trái đất gây ra từ các thiên thể khác như mặt trời và mặt trăng. SGP áp dụng cho các vật thể gần trái đất với chu kỳ quỹ đạo nhỏ hơn 225 phút. Mô hình nhiễu loạn không gian sâu rút gọn (Simplified Deep Space Perturbations - SDP) áp dụng cho các vật thể có chu kỳ quỹ đạo lớn hơn 225 phút, tương ứng với độ cao $5.877,5 \mathrm{~km}$. Mô hình SGP4 có sai số xấp xỉ $1 \mathrm{~km}$ theo epoch và tăng ở mức $1 \div 3 \mathrm{~km}$ mỗi ngày. Epoch là thời điểm mà các thông tin về quỹ đạo (vận tốc, tọa độ) của vật thể được thu nhận. Mô hình SGP đầu tiên được Kozai phát triển vào năm 1959, được Hilton và Kuhlman hoàn chỉnh vào năm 1966 và ban đầu được sử dụng bởi Trung tâm Kiểm soát Giám sát Không gian Quốc gia (sau đó là Mạng lưới Giám sát Không gian Hoa Kỳ) để theo dõi các vật thể trên quỹ đạo. Tại mỗi epoch, mô hình SDP4 có sai số không quá 10 km tại epoch (Lihua và nnk., 2016).

Để mô phỏng sự chuyển động vệ tinh viễn thám, nhóm tác giả đã tích hợp các thư viện Skyfield và MapWinGIS. Trong đó, Skyfield là thư viện hỗ trợ xử lý thiên văn được viết bằng ngôn ngữ python. Skyfield hỗ trợ khả năng tính toán vị trí của các ngôi sao, hành tinh, vệ tinh xung quanh trái đất. Với sự hỗ trợ của Skyfield, kết quả xử lý, tính toán các vị trí vật thể xung quanh trái đất có độ sai khác so với tính toán do Đài quan sát Hải quân Hoa kỳ cung cấp nằm trong khoảng $0,5 \times 10^{-4}$ arcseconds. MapWinGIS là một nền tảng C++ mã nguồn mở được sử dụng để lập trình các ứng dụng về hệ thông tin địa lý. Thư viện MapWinGIS hỗ trợ lập trình các ngôn ngữ như C\#, Visual Basic, nhằm hiển thị dữ liệu không gian địa lý và tương tác với các nguồn dữ liệu khác nhau. MapWinGIS hỗ trợ hầu hết các định dạng vector, raster được cung cấp bởi thư viện GDAL. 


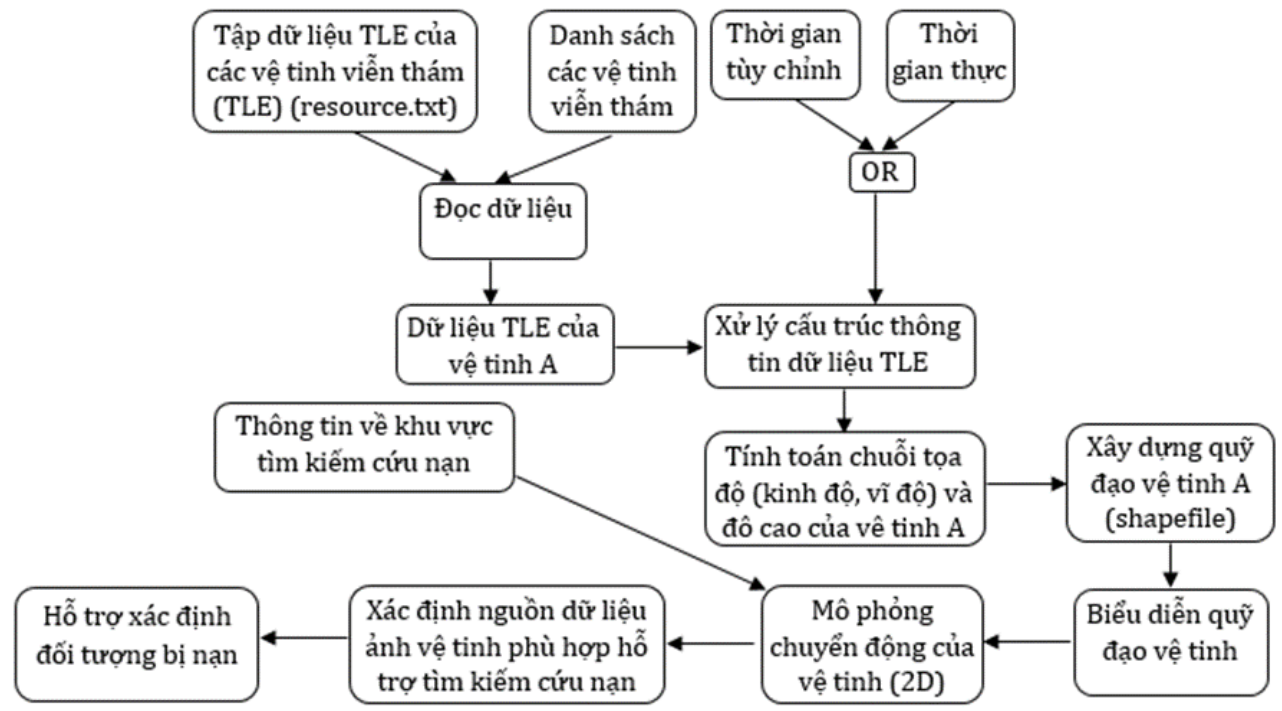

Hình 3. Mô hình mô phỏng sự chuyển động vệ tinh viễn thám dựa trên dũ liệu TLE.

Bảng 2. Tập phần tử hai dòng của một số vệ tinh viễn thám.

\begin{tabular}{|c|c|c|}
\hline Tên vệ tinh & Quốc gia & Dũ̃ liệu TLE \\
\hline SPOT 7 & Pháp & $\begin{array}{c}140053 \text { U 14034A 21006.84395187-.00000004 00000-0 88821-5 } 09995 \\
24005398.159476 .5199000163689 .7568270 .381314 .58570201347322\end{array}$ \\
\hline LANDSAT 8 & Hoa Kỳ & $\begin{array}{c}139084 \mathrm{U} \text { 13008A 21006.86666013.00000055 00000-0 22299-4 } 09999 \\
23908498.204679 .8071000114988 .8187271 .314314 .57119406408496\end{array}$ \\
\hline VNREDSAT 1 & $\begin{array}{l}\text { Việt } \\
\text { Nam }\end{array}$ & $\begin{array}{c}139160 \mathrm{U} 13021 \mathrm{~B} 21006.86105677 .0000008800000-026346-409996 \\
23916098.131286 .66390001197100 .7903259 .342514 .62942248409624\end{array}$ \\
\hline SENTINEL 2A & Châu Âu & $\begin{array}{c}140697 \mathrm{U} 15028 \mathrm{~A} 21006.89982786 .0000002500000-026201-409990 \\
24069798.567884 .19810001277100 .9535259 .178114 .30816781289553\end{array}$ \\
\hline SPOT 6 & Pháp & $\begin{array}{c}138755 U \text { 12047A } 21006.87809221-.0000001100000-074262-509997 \\
23875598.223876 .51860001346101 .0045259 .129714 .58544356443393\end{array}$ \\
\hline SENTINEL 2B & Châu Âu & $\begin{array}{c}1 \text { 142063U 17013A 21006.86484157 .00000037 00000-0 30883-4 } 09995 \\
24206398.569684 .1622000106781 .2333278 .896114 .30816124200460\end{array}$ \\
\hline KOMPSAT 5 & $\begin{array}{l}\text { Hàn } \\
\text { Quốc }\end{array}$ & $\begin{array}{c}139227 \text { U 13042A } 21006.79216435-.0000003500000-018027-509991 \\
23922797.6220194 .2256000224079 .788395 .661915 .04510016405097\end{array}$ \\
\hline
\end{tabular}

Dựa trên việc kết hợp nghiên cứu cơ sở khoa học lý thuyết chuyển động vệ tinh viễn thám kết hợp với nghiên cứu ứng dụng các thư viện hỗ trợ xử lý thiên văn, biểu diễn dữ liệu, đồ họa không gian địa lý, nhóm tác giả đã xây dựng mô hình mô phỏng sự chuyển động vệ tinh viến thám dựa trên dữ liệu TLE nhằm hỗ trợ tìm kiếm cứu nạn trên biển như Hình 3. Đầu vào của mô hình bao gồm: tập dữ liệu TLE của vệ tinh viễn thám (resource.txt) và thời điểm cần mô phỏng sự chuyển động của vệ tinh viễn thám.

Với mô hình này, các bước chính được thực hiện như sau:

- Đọc dữ liệu từ tập resources.txt nhằm trích xuất dữ liệu TLE của vệ tinh viễn thám. Tập dữ liệu resources.txt sẽ được cập nhập lại từ địa chỉ https://celestrak.com. Bảng 2 là danh sách TLE của một số vệ tinh viễn thám, được cập nhập ngày $16 / 1 / 2021$.

- Lựa chọn thời điểm mô phỏng sự chuyển động của vệ tinh viễn thám. Thời điểm này có thể được thiết lập tùy chỉnh hoặc theo thời gian thực.

- Xử lý cấu trúc thông tin dữ liệu TLE: lấy các thông tin cần thiết như: chu kỳ vệ tinh (period), độ cao vệ tinh (altitude),...

- Thực hiện chuyển đổi, tính toán ra tọa độ (kinh độ, vĩ độ) theo các bước nhảy là 1 giây nhằm tạo ra một tập danh sách các điểm.

- Xây dựng quỹ đạo vệ tinh dạng line và polygon từ tập các điểm vị trí (đã được xác định ở trên). Quỹ đạo polygon chính là đường dải quét của vệ tinh. Để xây dựng đường dải quét vệ tinh 
(chế độ nadir), cần phải tính toán buffer sang mỗi bên tính từ đường quỹ đạo: buffer = line + swath/2.

- Lập trình với thư viện MapWinGIS để biểu diễn đường quỹ đạo, dải quét vệ tinh cũng như mô phỏng chuyển động của vệ tinh theo thời gian.

- Kết hợp thông tin về khu vực tìm kiếm cứu nạn (phạm vi tìm kiếm cứu nạn) với chương trình mô phỏng sự chuyển động của vệ tinh viễn thám sẽ xác định được vệ tinh nào bay qua khu vực cần tìm kiếm cứu nạn, từ đó hỗ trợ việc xác định cung cấp nguồn dữ liệu ảnh vệ tinh cho hợp lý nhằm hỗ trợ việc xác định đối tượng trong tìm kiếm cứu nạn.

\section{Kết quả}

Kết quả nghiên cứu là nhóm tác giả đã xây dựng được chương trình mô phỏng sự chuyển động của vệ tinh dựa trên tập dữ liệu TLE. Chương trình có khả năng:

- Tính toán tọa độ, vận tốc, độ cao của vệ tinh viễn thám tại thời điểm hiện tại, thời điểm quá khứ

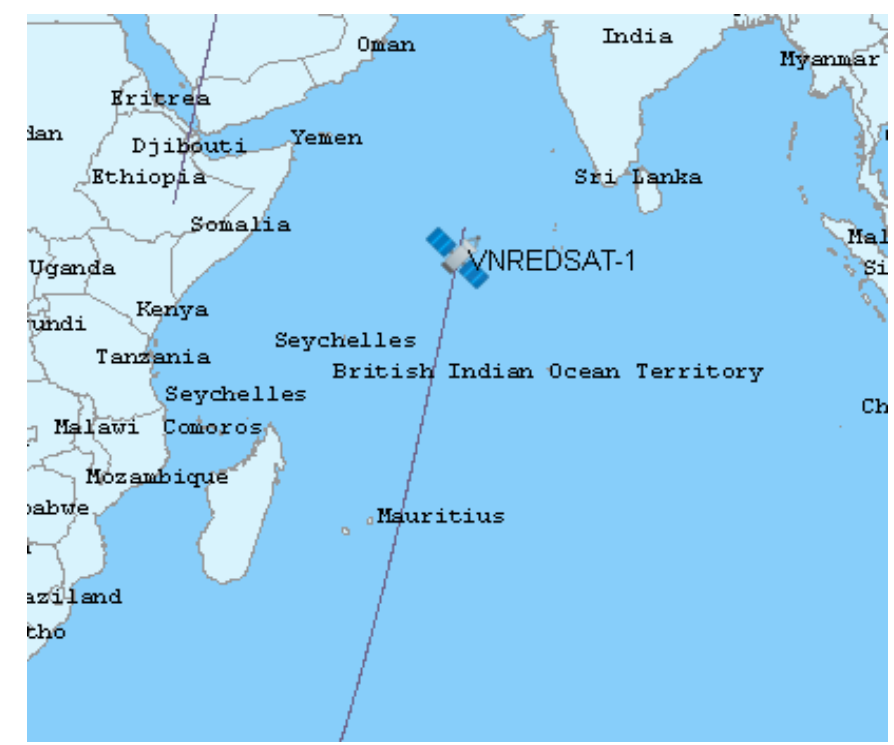

Hình 4. Mô phỏng sự chuyển động của vệ tinh viễn thám VNREDSAT 1.

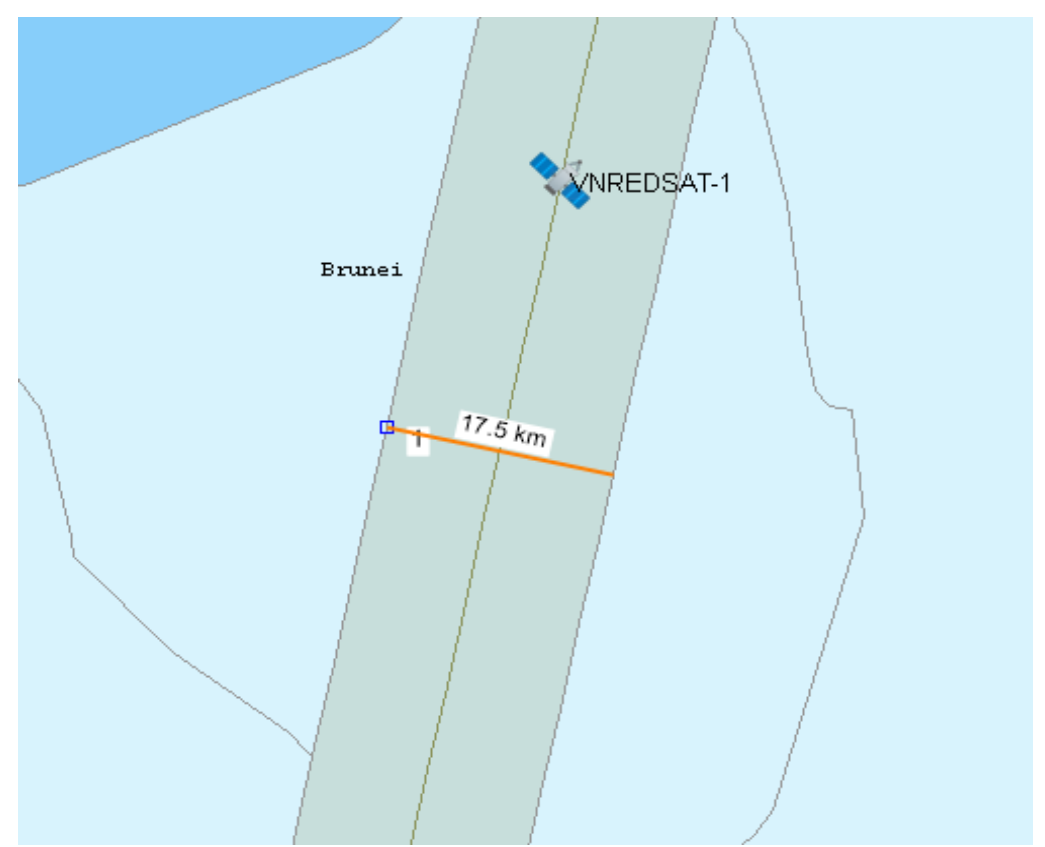

Hình 5. Mô phỏng một đoạn dải quét của vệ tinh viễn thám. 
cũng như khả năng dự đoán. Các vệ tinh viễn thám này được cung cấp bởi NORAD, gồm 399 vệ tinh.

- Xây dựng quỹ đạo vệ tinh theo chu kỳ (period).

- Mô phỏng sự chuyển động của vệ tinh (dạng 2D). Hình 4 mô phỏng sự chuyển động của vệ tinh VNREDSAT - 1 tại thời điểm 16/1/2021 6:21:7 am UTC.

- Mô phỏng sự chuyển động và dải quét của vệ tinh (dạng 2D). Hình 5 mô phỏng một đoạn dải quét của vệ tinh viễn thám VNREDSAT 1 (chế độ nadir).

Để đánh giá độ chính xác, nhóm tác giả đã thiết lập đánh giá kết quả thu nhận được so với nguồn dũ liệu từ địa chỉ NY2O (https://www.n2yo.com). NY20 cung cấp khả năng theo dõi thời gian thực và dự đoán đường quỹ đạo của vệ tinh. NY20 mô phỏng quỹ đạo phủ lên trên nền bản đồ Google Map. Đây là một trong những địa chỉ mô phỏng trực tuyến các vệ tinh được đánh giá cao. Việc đánh giá dựa trên các tiêu chí về độ cao, vị trí (kinh độ, vĩ độ). Bảng 3 là kết quả so sánh sai số giữa việc tính toán giữa địa chỉ NY20 với kết quả nghiên cứu của các vệ tinh VNREDSAT 1, Landsat8, Sentinel 2A, Sentinel 2B, SPOT 6, SPOT 7. Trong đó kí hiệu $\Delta d_{l}$ là độ chênh khoảng cách ngang; $\Delta d_{h}$ độ chênh cao.

\section{Thảo luận}

Từ kết quả nghiên cứu, nhóm tác giả rút ra một số nhận xét như sau:

- Chương trình được tạo ra đã cho thấy tính linh động trong mô phỏng sự chuyển động của vệ tinh viễn thám so với một số chương trình mô phỏng quỹ đạo vệ tinh trực tuyến như NY20 như khả năng thể hiện phạm vi dải quét của quỹ đạo vệ tinh, khả năng biểu diễn quỹ đạo vệ tinh ở thời điểm bất kỳ...

- Từ Bảng 3, tính toán được giá trị trung bình của độ lệch khoảng cách ngang $\left(\Delta d_{l-\text { mean }}\right)$ và độ chênh cao của vệ tinh $\left(\Delta d_{h-\text { mean }}\right)$ (Bảng 4$)$. Kết quả cho thấy độ lệch về vị trí (độ lệch ngang) và độ lệch cao giữa hai chương trình tính toán là khá nhỏ.

- Để đánh giá chi tiết về độ lệch nhóm tác giả đã tính toán tại 21 thời điểm khác nhau giữa chương trình tính toán được thực hiện bởi nhóm tác giả với chương trình NY2O đối với vệ tinh viễn thám VNREDSAT 1. Kết quả thu được như trên Hình 6 . Hình 6 thể hiên biểu đồ về độ chênh lệch tính toán, với cột màu xanh là độ lệch ngang, cột màu cam là độ lệch cao. Trục ngang là khoảng cách thời gian tính toán (đơn vị là giây). Trục dọc là khoảng cách (đơn vị km). Tính toán theo trung

Bảng 3. Đánh giá kết quả so với trang n2yo.com.

\begin{tabular}{|c|c|c|c|c|c|c|c|c|c|}
\hline \multirow{2}{*}{ Tên vệ tinh } & \multicolumn{4}{|c|}{ NY20 } & \multicolumn{2}{c|}{ Kết quả nghiên cứu } & \multicolumn{2}{c|}{ Đánh giá } \\
\cline { 2 - 10 } & $\begin{array}{c}\text { Thời gian } \\
\text { (UTC) }\end{array}$ & Vĩ độ & Kinh độ & $\begin{array}{c}\text { Độ cao } \\
(\mathrm{km})\end{array}$ & Vĩ độ & Kinh độ & $\begin{array}{c}\text { Độ cao } \\
(\mathrm{km})\end{array}$ & $\begin{array}{c}\Delta d_{l} \\
(\mathrm{~km})\end{array}$ & $\begin{array}{c}\Delta d_{h} \\
(\mathrm{~km})\end{array}$ \\
\hline VNREDSAT 1 & $2021-6-110: 20: 29$ & 19,04 & 112,71 & 685,77 & 18,983 & 112,701 & 685,761 & 6,39 & 0,009 \\
\hline VNREDSAT 1 & $2021-6-110: 38: 25$ & $-46,02$ & 96,95 & 701,96 & $-46,021$ & 96,946 & 701,976 & 0,39 & 0,016 \\
\hline VNREDSAT 1 & $2021-6-110: 40: 39$ & $-53,9$ & 93,62 & 705,19 & $-53,962$ & 93,593 & 705,227 & 6,91 & 0,037 \\
\hline Landsat 8 & $2021-6-110: 42: 20$ & $-45,68$ & 89,13 & 720,73 & $-45,743$ & 89,111 & 720,773 & 7,16 & 0,043 \\
\hline Landsat 8 & $2021-6-110: 47: 59$ & $-65,51$ & 77,81 & 728,14 & $-65,509$ & 77,811 & 728,16 & 0,12 & 0,02 \\
\hline Landsat 8 & $2021-6-110: 48: 49$ & $-68,32$ & 74,81 & 728,95 & $-68,318$ & 74,809 & 728,969 & 0,23 & 0,019 \\
\hline SENTINEL 2A & $2021-6-110: 49: 54$ & 29,96 & 104,99 & 792,3 & 29,957 & 104,995 & 792,29 & 0,54 & 0,01 \\
\hline SENTINEL 2A & $2021-6-110: 50: 51$ & 26,6 & 104,1 & 791,83 & 26,594 & 104,105 & 791,825 & 0,762 & 0,005 \\
\hline SENTINEL 2A & $2021-6-110: 44: 45$ & 48,07 & 110,93 & 795,83 & 48,068 & 110,931 & 795,819 & 0,193 & 0,011 \\
\hline SENTINEL 2B & $2021-6-110: 46: 27$ & $-42,26$ & $-71,27$ & 805,61 & $-42,199$ & $-71,287$ & 805,596 & 6,87 & 0,014 \\
\hline SENTINEL 2B & $2021-6-110: 51: 51$ & $-23,24$ & $-76,75$ & 797,88 & $-23,180$ & $-76,769$ & 797,867 & 6,903 & 0,013 \\
\hline SENTINEL 2B & $2021-6-110: 52: 54$ & $-19,46$ & $-77,68$ & 796,56 & $-19,460$ & $-77,675$ & 796,566 & 0,504 & 0,006 \\
\hline SPOT 6 & $2021-6-110: 55: 15$ & $-29,45$ & 86,39 & 709,22 & $-29,448$ & 86,386 & 709,228 & 0,402 & 0,008 \\
\hline SPOT 6 & $2021-6-112: 22: 22$ & 12,83 & 71,14 & 699,74 & 12,829 & 71,139 & 699,736 & 0,115 & 0,004 \\
\hline SPOT 6 & $2021-6-112: 25: 12$ & 2,55 & 68,82 & 700,36 & 2,5477 & 68,921 & 700,359 & 11,23 & 0,001 \\
\hline SPOT 7 & $2021-6-110: 57: 01$ & 34,64 & $-95,01$ & 701,76 & 34,699 & $-95,027$ & 701,759 & 6,77 & 0,001 \\
\hline SPOT 7 & $2021-6-112: 12: 33$ & $-49,33$ & $-98,69$ & 717,78 & $-49,271$ & $-98,709$ & 717,776 & 6,62 & 0,004 \\
\hline SPOT 7 & $2021-6-112: 23: 53$ & $-8,49$ & $-109,86$ & 702,42 & $-8,4876$ & $-109,86$ & 702,427 & 0,39 & 0,007 \\
\hline
\end{tabular}


Bảng 4. Đánh giá về độ lệch trung bình.

\begin{tabular}{|c|c|c|c|c|c|c|}
\hline \multirow{2}{*}{ Tên vệ tinh } & \multicolumn{2}{|c|}{ Độ chênh khoảng cách ngang $\left(\Delta d_{l}\right)$} & \multicolumn{3}{|c|}{ Độ chênh cao $\left(\Delta d_{h}\right)$} \\
\cline { 2 - 7 } & $\Delta d_{l-\max }$ & $\Delta d_{l-\min }$ & $\Delta d_{l-\text { mean }}$ & $\Delta d_{h-\text { max }}$ & $\Delta d_{h-\text { min }}$ & $\Delta d_{h-\text { mean }}$ \\
\hline VNREDSAT 1 & 6,91 & 0,39 & 4,56 & 0,037 & 0,009 & 0,021 \\
\hline Landsat 8 & 7,16 & 0,12 & 2,53 & 0,043 & 0,019 & 0,027 \\
\hline SENTINEL 2A & 0,762 & 0,193 & 0,498 & 0,011 & 0,005 & 0,042 \\
\hline SENTINEL 2B & 6,903 & 0,504 & 4,76 & 0,14 & 0,006 & 0,092 \\
\hline SPOT 6 & 11,23 & 0,115 & 3,916 & 0,008 & 0,001 & 0,004 \\
\hline SPOT 7 & 6,77 & 0,39 & 4,59 & 0,007 & 0,001 & 0,003 \\
\hline
\end{tabular}

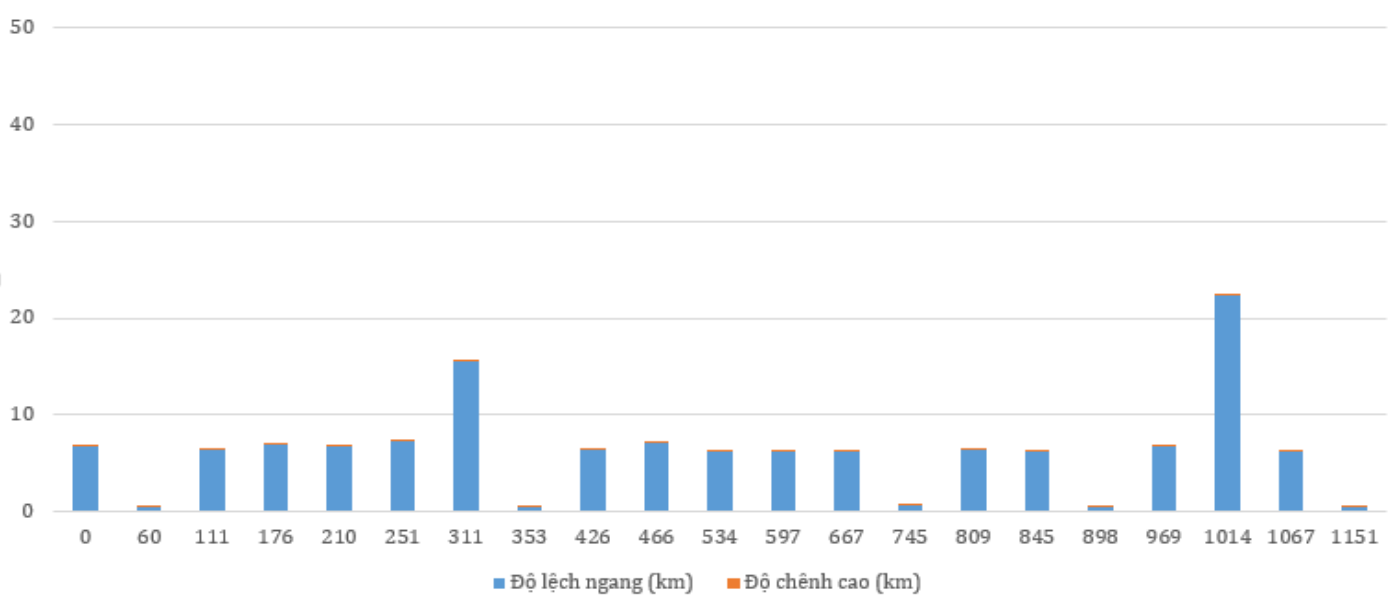

Hình 6. Độ lệch cao và độ chênh ngang được tính toán giũa ny2o và nghiên cúu.

bình, độ lệch ngang là 6,3 km và độ chênh cao là $0,025 \mathrm{~km}$.

- Chương trình mô phỏng có giao diện tiếng Việt và không cần kết nối internet, tính toán được quỹ đạo vệ tinh trong quá khứ, hiện tại và dự báo tương lai. Chương trình vẫn đang được nhóm tác giả tiếp tục phát triển để hoàn thiện thêm môt chức năng như đưa ra thứ tự ưu tiên của dữ liệu ảnh vệ tinh khi cần tìm kiếm cứu hộ cứu nạn trên biển, xuất thông tin báo cáo,...

\section{Kết luận}

Tập dữ liệu phần tử hai dòng thường được sử dụng để mã hóa các thông tin quỹ đạo liên quan tới các vật thể quay quanh trái đất, trong đó có các vệ tinh viễn thám. Với việc tích hợp các nền tảng phát triển ứng dụng mã nguồn mở như Skyfield, MapWinGIS...và các ngôn ngữ lập trình như C\#, Python, nhóm tác giả đã xây dựng được chương trình mô phỏng sự chuyển động của vệ tinh viễn thám dựa trên tập dữ liệu tập phần tử hai dòng. Chương trình mô phỏng quỹ đạo này không chỉ biểu diễn vị trí của vệ tinh tại thời gian thực mà còn thể hiện được độ rộng dải quét của vệ tinh hay vị trí của vệ tinh tại thời điểm bất kỳ. Điều này có giá trị ý nghĩa thực tiễn cao, bởi đây sẽ là một trong những thành phần quan trong trong hệ thống thông tin tích hợp hỗ trợ tìm kiếm cứu nạn trên biển dựa trên các nền tảng công nghệ địa không gian như viễn thám, hệ thông tin địa lý mà nhóm tác giả sẽ tiếp tục phát triển trong thời gian tới.

\section{Lò̀i cảm ơn}

Nhóm tác giả cảm ơn sự tài trợ về kinh phí từ đề tài nghiên cứu cứu khoa học cấp Bộ Quốc Phòng, mã số 2018.73.041; sự tạo điều kiện của Bộ môn Trắc địa Bản đồ - Viện Kỹ thuật công trình Đặc biệt - Học viện Kỹ thuật Quân sự để nghiên cứu này được tiến hành thuận lợi.

\section{Đóng góp của các tác giả}

Nguyễn Sách Thành - mục đích nghiên cứu, phạm vi nghiên cứu, phương pháp và các kết quả đạt được; Lê Vũ Hồng Hải - phương pháp luận, phân tích dữ liệu; Đoàn Văn Chinh - đánh giá, so sánh kết quả nghiên cứu. 


\section{Tài liệu tham khảo}

Aleksander, A. L., David, J. G., Roberto, A., Camilla, C., Hugh, G. L., Quirin, F., Tim F. (2016). Processing two line element sets to facilitate re - entry prediction of spent rocket bodies from the geostatonary transfer orbit, The 6th International Conference on Astrodynamics Tools and Techniques (ICATT).

Bùi, D. C., Chu, X. H., Nguyễn, M. N., Bùi, Q. H., Hoàng, H., \& Phạm, Đ. T. (2018). Phân tích quỹ đạo hoạt động để đánh giá khả năng phối hợp chụp ảnh của các hệ thống vệ tinh nhỏ, thử nghiệm với vệ tinh VNREDSat - 1 và BKA. Tạp chí Khoa học và Công nghệ Việt Nam, 60(6), 913.

Carolin, F., Thomas, S., (2012). Accuracy of Two Line - Element Data for Geostationary and High - Eccentricity Orbits, Journal of Guidance Control and Dynamics, 35(5), 1483-1491.

Chang, H. C., Byoung, S. L., Jeong, S. L., \& Kim, J. W. (2002). NORAD TLE type orbit determination of leo satellites using gps navigation solutions, Journal of Astronomy \& Space Sciences, 19(3), 197-206.

David, A. V., \& Paul, J. C., (2012). Two Line Element sets - practice and use, The $63^{\text {rd }}$ International Astronautical Congress.

Francesco, T., Mauro, M., Riccardo, L., Marco, G., Andrea, M., Martina, A., Stefano, T., \& Francesco, B. (2015). Space shepherd: search and rescue of illegal immigrants in the mediterranean sea through satellite imagery, The International Geoscience and Remote Sensing Symposium 2015, 4852 - 4855.

Flemming, H. (2001). DTU Satellite Systems and Design Course Orbital Mechanics.

Jean, L. L. (2017). Space Strategy, First Edition, ISTE Ltd and John Wiley \& Sons, Inc, United Kingdom, 285-288.
Jesse, Re. (2013). SARSAT Overview. SAR Controllers Training 2013.

Kathleen, R. (2015). Orbit Determination from Two Line Element Sets of ISS - Deployed CubeSats, The 29th Annual AIAA/USU Conference on Small Satellites.

Lihua, M., Xiaojun, X., Feng, P. (2016). Accuracy assessment of geostationary - earth - orbit with simplified perturbations models, Artificial Satellites, 51(2), 55-59.

Ngô, Đ. Q. (2019). Hội nghị công tác tìm kiếm cúu nạn trên biển 2019. Văn phòng Ủy ban Quốc gia ứng phó sự cố thiên tai và Tìm kiếm cứu nạn.

Norad Two - Line Orbital Element Set File, https://ai-solutions.com/.

Shkelzen, C., Mickey, F., Jesse, R., \& Eric, F. (2010). Satellite Image Analysis for Disaster and Crisis Management Support, The 52 ${ }^{\text {nd }}$ International Symposium ELMAR - 2010, 173-176.

Stefan, V., Thomas, K., Torsten, R., Ralph, K., Klaas, S., \& Harald, M., (2007). Satellite Image Analysis for Disaster and Crisis Management Support, IEEE Transactions on Geoscience and Remote Sensing, 45(6), 1520-1528.

Szabo, P., Gombikova, K., Ferencova, M., \& Kosuda, M. (2019). Keplerian Orbit and Satellite skCUBE, New Trends in Aviation Development. 174-179.

Tim, F., Holger, K., \& Heiner, K. (2008). Assessment and Categorization of TLE Orbit Errors for the US SSN Catalogue, Proceedings of the Advanced Maui Optical and Space Surveillance Technologies Conference.

Tom, K., Doyle, H., Kris, H., Maj, D. S. (2007). Satellite Maneuver Detection Using Two - line Element (TLE) Data, The Advanced Maui Optical and Space Surveillance Technologies Conference. 